\title{
Camus entre a peste e a pandemia
}

\author{
Camus between plague and pandemic
}

\section{Bethânia Silva Tristão ${ }^{1}$ Lúcio Álvaro Marques ${ }^{2}$ Yani Aparecida Oliveira ${ }^{3}$}

\author{
1 Universidade Federal do Triangulo Mineiro \\ Orcid: http://orcid.org/0000-0003-1206-0249 \\ 2 Universidade Federal do Triangulo Mineiro \\ Orcid: http://orcid.org/0000-0002-7571-0977 \\ 3 Universidade Federal do Triangulo Mineiro \\ Orcid: http://orcid.org/0000-0003-3827-9556
}

RESUMO: O artigo será dividido em introdução, onde apresentaremos $A$ Peste de Albert Camus, retratando a cidade de Oran que é acometida pela peste. Logo em seguida, em tópicos analisaremos cada personagem e/ou situação de Oran em paralelo com nossa realidade, a saber: à luz da pandemia do novo coronavírus (Covid-19). Situaremos a análise em países mundo a fora como exemplo para apresentarmos uma reflexão mais assertiva, daremos atenção maior na realidade brasileira e como a população enfrenta a sua pior e maior crise sanitária. Trazendo com clareza a importância dos profissionais da área de saúde e pesquisa em um sistema de saúde precário, falaremos também das consequências geradas pelas informações que tomam proporçòes de extrema velocidade e ao mesmo tempo, o trabalho para esclarecer a falsa informação (FakeNews) em relação ao novo coronavírus. Discorreremos também sobre o discurso negacionista das autoridades e empresários em relação a pandemia em dizer que o vírus é apenas uma gripezinha, colocando a economia com mais importante que a vida. Apontaremos as medidas de proteção que tem o distanciamento social como uma das maiores formas de proteção e a dificuldade do país para evitar a disseminação do vírus em meio a uma sociedade que vivencia uma das maiores desigualdades sociais do mundo.

Palavra-chave: Saúde; pandemia; informação.

ABSTRACT: The article will be divided into an introduction, where we will present "A Peste" by Albert Camus, portraying the city of Oran that is affected by the plague. Then, in topics, we will analyze each character and/or situation of Oran in parallel with our reality: in light of the pandemic of the new coronavirus (Covid19). We will place the analysis in countries around the world as an example to present a more assertive reflection, we will give greater attention to the Brazilian reality and how the population faces its worst and biggest health crisis. We will present with clarity the importance of health and research professionals in a precarious health system, we will also talk about the consequences generated by the information that takes on extremely fast proportions and, at the same time, how hard it is to clarify false information (Fake News) about the new coronavirus. We will also discuss the denialist discourse of the authorities and businesspeople in relation to the pandemic in saying that the virus is just a little cold, placing the economy as more important than life. We will point out the protection measures that have social distance as one of the greatest forms of protection and the country's difficulty in preventing the spread of the virus in the midst of a society that experiences one of the greatest social inequalities in the world.

Keywords: Health; pandemic; information. 


\section{Introdução}

Albert Camus (1913-1960) em A Peste (1947) realiza uma crônica contando a história de Oran que se passa na década de 40. A obra de Camus está dividida em partes e narrada pelo médico Bernard Rieux. O autor nos remete a várias visões da história levantando questões como sobre guerra, religião, suicídio, pena de morte, individualismo e vida em sociedade. No entanto, nosso olhar será sobre a peste e seus efeitos, as reações causadas na cidade com o aparecimento da epidemia para assim fazer uma relação com os dias atuais. O narrador apresenta os personagens e a situação de Oran em meio a uma quarentena, a saber: a reação do poder público quanto a publicar ou não a gravidade da doença, a visão dos médicos, a forma de exílio e o número crescente de mortes.

O martírio fica evidente quando a cidade é fechada, até mesmo o envio de cartas é proibido. De forma clara e muito impactante, Rieux narra a situação precária do hospital, além de locais que foram transformados para o atendimento das vítimas e a forma de isolamento das famílias acometidas pela doença. Os enterros, rituais que a partir de um momento já não eram mais possíveis, foram substituídos pelos sepultamentos de todos juntos sem distinções de sexo e mais tarde por falta de espaço, eram lançados ao mar.

Muitos acontecimentos descritos por Albert Camus faz parte do nosso hoje, descobrindo o pior da sociedade e revelando a empatia e solidariedade. Que ironia, em sua última frase do livro depois de passada do surto, Rieux observava a felicidade das pessoas e pensava:

Por que ele sabia o que a multidão eufórica ignorava e se pode ler nos livros: o bacilo da peste não morre nem desaparece nunca, pode ficar dezenas de anos adormecidos nos móveis e na roupa, espera pacientemente nos quartos, nos porões, nos baús, nos lenços e na papelada. E sabia, também, que viria talvez o dia em que, para desgraça e ensinamento, dos homens a peste acordaria os ratos e os mandaria morrer numa cidade feliz. (CAMUS, p. 174)

De fato ficou adormecida por anos e agora despertou com um novo formato, não só em uma cidade no interior da França, mas em todo mundo de forma impiedosa, trouxe de volta figuras tão bem descritas no imaginário do autor. Assim, comparamos A Peste de Albert Camus à pandemia do SARS-CoV-2 (Covid19) em nosso tempo e a forma de propagação do vírus. No entanto, o que a literatura nos ensina para enfrentarmos a nova peste?

\section{Doutor Bernard Rieux: ler o hoje com os olhos de ontem}

De acordo com a Organização Pan Americana de Saúde (OPAS), em anúncio feito pelo diretor geral da Organização Mundial da Saúde (OMS), Tedros Adhanom Ghebreyesus, no dia 11 de março de 2020, anunciou que o coronavírus Síndrome Aguda Grave 2 (SARS-CoV-2), doença de Covid-19 (Coronavírus Disease 2019), a partir daquele momento era considerado como pandemia, vírus que apareceu na China e foi identificada por um surto de pneumonia em comum de pessoas do Mercado Atacadista de Frutos do Mar, na cidade de Wuhan, tornando-se uma Emergência de Saúde Pública de Importância Internacional (ESPII) em janeiro desde ano. A doença já foi registrada em mais de 180 países até o momento, sendo o Brasil o primeiro país da América Latina a ter o teste positivo, em 26 de fevereiro de 2020.

No Brasil, no entanto, medidas já haviam sendo tomadas para contenção do vírus pela Secretaria de Vigilância em Saúde e do Ministério da Saúde (SVS/MS), juntamente com outros órgãos para ação de prevenção e enfrentamento da pandemia, conforme Portaria n 188, de 3 fevereiro de 2020, "considerando 
que o evento é complexo e demanda esforço conjunto de todo o Sistema Único de Saúde(SUS) para identificação da etiologia dessas ocorrências e adoção de medidas proporcionais e restritas aos riscos”, (DOU, 2020)

Até a data de hoje 25 de maio de 2020, foram divulgados pelo Ministério da Saúde, 363.211 casos confirmados, destes 22.666 vieram a óbito e 149.911 se recuperaram. O país assume posição de destaque em níveis de contaminação pelo vírus e tem nos profissionais de saúde seus aliados para seu combate. Estes assumiram a linha de frente fazendo a diferença na contenção ao novo coronavírus, por esta razão, neste período de quarentena, o distanciamento dos que trabalham diretamente com o vírus é diferente do resto da população, tais profissionais se isolam em seus locais de trabalho.

Conforme a crônica Evolução nos tempos do Coronavírus da Revista Ser Médico, a médica Carolina Mineli Martines (2020, p.16,17), residente em cirurgia geral descreve a situação do Hospital das Clínicas em São Paulo, com a chegada da doença, segundo a médica o hospital realoca pacientes para outros complexos, "as férias de todos os colaboradores são suspensas, médicos assistentes e residentes são deslocados de suas funções originais para exercer o trabalho mais urgente: combate a Covid-19”'.

Trabalhando ativamente para tentar controlar o desconhecido, lidando com uma rotina muito estressante e longe de seus familiares, os profissionais da linha de frente, mesmo com temor, são incansáveis para conservar a vida de seus pacientes. Segundo Carolina Mineli, (2020, p.16,17) o trabalho é mais difícil por falta de "estudos científicos conclusivos, sem mencionar o inacreditavelmente rápido esgotamento dos EPIs".

A luta contra o vírus e a mudança no cotidiano da sociedade nos faz confundir literatura com a vida real, na crônica $A$ peste, o Dr. Bernard Rieux representa a classe médica, este tem papel fundamental desde o início da história, tomando decisões de forma coerente com sua profissão e consciência, assim como muitos profissionais da linha de frente tem enfrentado o novo coronavírus.

Ao mesmo tempo que o personagem "Dr. Rieux" tem equilíbrio de quais decisões tomar, evitando os exageros, prevenindo para que nenhuma atitude impensada seja tomada e buscando meios de controle da peste, temos como exemplo o trabalho árduo dos profissionais da saúde, a precariedade no sistema nos levando a pensar em um trecho do livro onde doutor Rieux diz: "não era fácil, por exemplo, dirigir-se a esse hospital auxiliar — e agora havia três — de que estava encarregado" (CAMUS, p.51).

O que vemos na nossa realidade? São hospitais construídos em lugares improvisados, a falta de respiradores, de leitos de UTIs caso haja um aumento de pessoas doentes e a falta de equipamentos de proteção individual (EPI’s), necessários para quem está em contato com o vírus. Equipamentos como máscaras, aventais, viseiras fazem toda diferença para os trabalhadores de saúde que, além de enfrentarem algo novo, abdicam de suas vidas e lutam contra essa falta de equipamento com uma pressão psicológica trabalhando de forma mais vulnerável.

Percebemos como as angústias e lutas do doutor Rieux são tão vivas nos dias atuais. A Dra. Caroline Mineli (2020, p.16,17), relata que toda manhã antes de entrar no quarto isolado de um de seus pacientes se paramenta toda e com um "sorriso no rosto - que não pode ser visto devido à máscara N95 - e com a esperança de encontrar seu paciente saturando satisfatoriamente bem com o cateter nasal, apesar dos pulmões tomados pelo SARS-CoV2 (agente etiológico da Covid-19)".

Logo, esta fala nos transporta para o pensamento do personagem de Albert Camus: "durante todo o dia, o médico sentiu aumentar a pequena vertigem que o atacava a cada vez que pensava na peste. Finalmente, reconheceu que tinha medo" (CAMUS, p.35), demonstrando medo sobre o que acontecia.

Pensamento que nos conduz para o hoje, onde fica claro o medo que os profissionais de saúde 
enfrentam e como eles têm papel fundamental para o combate à pandemia, assim como afirma Dra. Caroline Minelli (2020, p.16,17) dizendo que o novo coronavírus é a "doença da solidão e do medo, medo de ter suas vidas nas mãos de pessoas estranhas, das quais só avistamos olhos por trás da face shield, dos óculos das máscaras. Medo de morrer sozinho. Medo de mal ter um enterro digno”.

\section{Doutor Richard}

Em meio à pandemia muitos posicionamentos se diferem, parte destes negligenciam as informações obtidas, ignorando à crescente curva nos gráficos que mostram a disseminação da doença. Visto que tais julgamentos são vindos de autoridades do governo, estes acreditam que o vírus é sem gravidade e pode ser tratado como apenas um "resfriado".

Reconhecemos em Richard, uma figura da imaginação do autor, muitas pessoas da nossa realidade como governantes e empresários que têm um discurso negacionista para a gravidade do vírus Covid-19.

N'A Peste, Dr. Richard companheiro de profissão do médico Rieux, secretário da associação dos médicos de Oran, é um daqueles personagens que acredita que a doença era muito mais pânico e sem gravidade, teve em suas mãos uma grande responsabilidade, porém preferiu ser lento em ações de combate à peste e até mesmo referindo-se a ela como um tipo diferente de febre, comportamento visto entre muitos líderes políticos e empresários, mesmo que isso custe vidas, pois para muitos o mundo econômico não pode parar.

Conforme De Troi e Quintilio (2020, p. 2) em diversos períodos da epidemia "o papel das autoridades, em princípio, era negar o que estava ocorrendo. Sob o argumento de que não era necessária a preocupação, evitando 'histeria' e 'alarmismo', atitudes quase sempre escondiam interesses políticos e econômicos". Richard na narrativa tem em sua opinião que "não se devia ceder ao pânico. Tratava-se de uma febre com complicações inguinais e era tudo o que se podia dizer, já que as hipóteses, na ciência como na vida, são sempre perigosas" (CAMUS, p. 31).

Não muito diferente da ficção, a fala "uma febre com complicação" nos leva à declaração do presidente Jair Messias Bolsonaro tratando o novo coronavírus como uma "gripezinha”, desrespeitando não só as vítimas, mas o mundo com tal afirmação, além de tal fala ir contra o seu Ministério da Saúde. É o que podemos observar em texto divulgado pelo site, Autre Brésils em 8 de abril com o título: Bolsonaro comete um crime contra a humanidade: a denúncia é apresentada ao Tribunal Penal Internacional (tradução nossa) ${ }^{1}$.

Todavia, o que vemos são pessoas lutando contra a Covid-19 num país com grande desigualdade social, onde pouco se sabe sobre a doença, governadores vão contra o chefe maior do poder executivo que de forma negligente subestima a gravidade do vírus? Moutinho (2020, p. 7) em seu artigo nos relata que "a sociedade brasileira está convivendo com o negacionismo e com uma profunda crise política, na qual tem sido frequente o desrespeito às vidas perdidas e ao luto dos que sobreviveram aos entes amados".

O Presidente de forma imprudente apoiou manifestações, contrariando medidas de proteção da Organização Mundial de Saúde (OMS) e do seu próprio . Ministério. Em outros momentos, ele voltou atrás e mudou de acordo com as opiniões das autoridades do governo como também das pesquisas feitas pela aceitação dos seus discursos e conforme a reação das notícias veiculadas pela mídia, tenta amenizar sua fala.

Num pronunciamento feito para rádio e televisão e via internet, o Presidente da República, Jair Messias Bolsonaro, em 24 de março de 2020, reforçou as atitudes tomadas pelo Ministério da Saúde, mostrou

1 “Bolsonaro commet un crime contre L'humanité: La plainte est déposée devant La Cour pénale Internationale." 
um cuidado com o grupo de risco, porém, ao mesmo tempo, diz que o distanciamento social prejudica a economia do país e, de forma egoísta, acredita que a maioria dos infectados são assintomáticos, trazendo informações pessoais sobre o seu físico atlético e algumas informações que não foram pertinentes ao momento. Para melhor compreensão citaremos sua fala em relação à pandemia que parou o mundo:

[...] Mas, o que tínhamos que conter naquele momento era o pânico, a histeria e, ao mesmo tempo, traçar a estratégia para salvar vidas e evitar o desemprego em massa. [...] O que se passa no mundo tem mostrado que o grupo de risco é o das pessoas acima dos 60 anos. Então por que fechar escolas? Raros são os casos fatais de pessoas sãs com menos de 40 anos de idade. $90 \%$ de nós não teremos qualquer manifestação, caso se contamine. [...] No meu caso particular, pelo meu histórico de atleta, caso fosse contaminado pelo vírus não precisaria me preocupar, nada sentiria ou seria, quando muito, acometido de uma gripezinha ou resfriadinho, como bem disse aquele conhecido médico daquela conhecida televisão. [...] Sem pânico ou histeria, como venho falando desde o princípio, venceremos o vírus e nos orgulharemos de estar vivendo nesse novo Brasil, que tem tudo, sim, tudo para ser uma grande nação. (Brasil, 2020)

O presidente Jair Bolsonaro, faz comparação com outro país que por motivos econômicos resolveram tardiamente pelo distanciamento social, faz críticas à imprensa, e demonstra uma grande preocupação em relação à histeria e ao pânico da população, notável no discurso do personagem Richard d'A peste. Deste modo, após seu discurso, pessoas começaram a apoiar o "isolamento vertical", onde apenas o grupo de risco deveria fazer o distanciamento. A partir desse discurso houve um relaxamento em alguns Estados quanto ao confinamento e a maneira de ser feito, aderindo ao "isolamento vertical" apresentado pelo Presidente, onde, para dar certo, teríamos que separar a população em dois grupos: o das pessoas em riscos, de um lado, e os demais, numa posição de salve-se quem puder, do outro. No entanto, o presidente faz da situação mais um momento de populismo com suas declarações polêmicas e com o slogan o "Brasil não pode parar", deixa claro o descaso com vidas que poderão ter fim com o vírus.

\section{Imprensa}

$\mathrm{Na}$ narração $A$ Peste, a imprensa, através de todos os meios, jornais e panfletos são distribuídos na cidade. Nela se afirmava: “a imprensa, tão discreta nos casos dos ratos, já não mencionava nada. É que os ratos morreram na rua e os homens, em casa" (CAMUS, p. 23). As notícias nos jornais diziam: "no dia seguinte ao da reunião, a febre deu mais um pequeno salto, se bem que de uma forma benigna, já que se contentaram em fazer algumas alusões" (CAMUS, p. 32). Na história de Albert Camus fez-se um alarde pela aparição dos ratos mortos e dos doentes pela cidade. Porém, durante a peste, pouco se falou de sua proporção, mantendo discrição quanto aos acontecimentos e a quantidade de pessoas doentes.

Observamos a época em que o livro foi publicado é notável a diferença dos meios de comunicação com a atualidade: de 1947 a 2020, houve largo avanço tecnológico. Além de jornais, rádio e televisão temos também à internet, sendo fundamental para a vida moderna, desde as publicações de novos artigos e dados sobre os novos conhecimentos, que alcançam grande importância até a forma como a medicina que lida com algo novo em relação ao Covid-19, por exemplo.

Os meios de comunicação hoje são usados para transmitir informações sobre os acontecimentos e pontos de vista sobre todos os tipos de conteúdo, além da facilidade tecnológica em questão de minutos a notícia é muitas vezes repassada e compartilhada atingindo muitos grupos de pessoas. Nesse momento de pandemia, as informações são disseminadas (viralizam) com a mesma velocidade que o vírus, transformando os meios de comunicação em instrumento fundamental para formação de opinião e esclarecimento. Deste 
modo, a mídia e a tecnologia em torno do Covid-19, principalmente o meio digital, é uma ferramenta importante para publicações do meio científico e para transmitir novos dados, já que muitas especulações são feitas em virtude do parco conhecimento científico sobre o novo coronavírus.

De acordo com o texto Da desinformação ao Caos: um análise das Fake News frente à pandemia do Coronavírus (Covid-19) no Brasil (in SOUSA Jr.et al., 2020, p. 332) inserir nas referências), a tecnologia vem se transformando ao longo do tempo, fornecendo na sociedade a agilidade ao seu acesso, porém com tanta facilidade o usuário comum dessas tecnologias tornou-se um "prosumer, isto é, ele não apenas consome o conteúdo da internet como também interage, cria e compartilha com grande alcance, tornando-se, ao mesmo tempo, consumidor e produtor de conteúdos on-line". Isso remete-nos a um mundo globalizado e digitalizado, através de uma tecnologia avançada e com o distanciamento social e a internet interligando todo o mundo, sendo instrumento necessário para muitos garantirem seus trabalhos, sem falar da importância que ela toma na educação de base e na pesquisa contra o vírus diante da pandemia.

Paralelamente, sabendo disso, muitas informações são compartilhadas sem a devida avaliação de veracidade, fazendo com que notícias causem pânico e medo pela disseminação de Fake News. Conforme Sousa Jr. et al., (2020, p. 336) as Fakes News são informações espalhadas através de mídias editadas para obter "a atenção do leitor no intuito de desinformá-lo e obter algum tipo de vantagem sobre ele, sem que haja fonte verídica determinada, mas apresentando uma maquiagem que transparece uma aparente credibilidade para quem as recebe".

Os impactos negativos dessas Fake News são ainda mais visíveis com a gravidade do novo coronavírus, fazendo com que o Ministério da Saúde disponibilize número de WhatsApp para informar o cidadão sobre vídeos, mídias e sua suposta veracidade. Segundo De Troi e Quintilio (2020, p. 5) muitos membros da comunidade científica, além de cuidar para que a população seja informada da transmissão do vírus e a proporção da sua seriedade, "cientistas no mundo inteiro têm utilizado seu precioso tempo para desfazer informações mentirosas ou convencer governantes oportunistas de que a ciência pode auxiliar na tomada de decisões que podem evitar a morte de vidas".

A luta enfrentada não é somente contra a Covid-19, mas também contra mentiras que circulam livremente por todos os lugares através da mídia. Mostrando como a mente humana trabalha em meio às incertezas e o quanto é importante fazer uma seleção das informações recebidas.

\section{Sr. Cottard: a voz do mercado não silencia}

Voltemos nossa atenção para o capital. Então, para correlacionar um personagem capitalista da literatura com muitos empresários e autônomos que viram na pandemia uma oportunidade de enriquecer, partiremos da definição do termo capital de forma simples a partir do texto de Ladislau Dowbor com o título; O que é capital? (DOWBOR, 2003, p.n) para o autor a definição do termo capital é "o conceito mais próximo da riqueza. de forma geral, o objetivo explícito de quem maneja capitais num sistema capitalista é tornar-se rico".

O que nos remete ao Sr. Cottard, personagem da crônica $A$ Peste, oportunista que tem como frase favorita: "os grandes sempre comem os pequenos" (CAMUS, p. 34). Expressão que nos faz pensar na época atual, onde grandes empresas se viram imersos na crise econômica associada à pandemia, no entanto, a crise verdadeira, vem sendo arrastada ao longo da existência do sistema capitalista.

No texto publicado pelo Movimento Revista no mês de março em uma organização de autores com o título Coronavírus: a falência do sistema capitalista e a defesa radical do SUS (MINOWA et al., 2020, n.p) afirma que 
"as doenças que enfrentamos e a forma com que os diferentes grupos sociais se impactam por elas tem ligação direta com arranjo estrutural de organização do trabalho e das condições de vida das pessoas”. Este tornou-se tão amplo e rápido que um vírus em questão de horas pode atravessar continentes, ainda de acordo com a mesma fonte que "no capitalismo neoliberal globalizado, é quase impossível que doenças infecciosas não assumam proporções pandêmicas". Ou seja, no decorrer de sua expansão o modo de produção capitalista veio transformando o agir das pessoas, a acessibilidade e o ambiente, além de dividir e desvalorizar a força de trabalho o sistema acelerou a globalização, o fluxo de mercadorias e assim consequentemente a interdependência dos países. Conforme Anjuli Tostes, Pandemia e nova ordem social:

o que temos visto desse sistema são os seus efeitos devastadores em termos de aumento da poluição e do aquecimento global, da cultura do descarte e do consumismo, das desigualdades extremas, das centenas de milhões de vidas em absoluta pobreza, das familias de refugiados fenecendo à deriva. E das pandemias e catástrofes evitáveis. (TOSTES, 2020, p. 35)

Com a visão focada no lucro, o capitalismo nos faz questionar a quantidade de vírus que vem aparecendo, seja pelo rápido crescimento industrial gerando alteração no clima, seja por não falar do interesse de potências na fabricação de armas biológicas e de pesquisas de certos laboratórios onde fica evidente o vínculo direto de um vírus com a sociedade capitalista. Para além das causas, as consequências também são preocupantes, principalmente no momento em que estamos vivendo com o vírus Covid-19, uma crise sanitária global e social, aliada com a crise econômica, fazendo crescer ainda mais o índice do desemprego, o alargamento da faixa de desigualdade entre as classes sociais.

No entanto, com orientações de afastamento social dadas pela Organização Mundial da Saúde (OMS) e demais órgãos aliados, o sistema é ainda mais cruel, as necessidades para subsistência como alimentação, transporte e as condições de trabalho pioraram com a pandemia, escancarando ainda mais as desigualdades sociais, pois a população das margens está sendo explorada não em um consumo de desejo, mas de necessidade, exemplo disso: é o aumento da cesta básica, itens de limpeza e higiene, o uso de máscaras, o álcool em gel e outros meios de prevenção, transformam determinados setores do comércio.

O Sr.Cottard, nos faz lembrar esta relação de empresas e pessoas da nossa realidade, já que a sociedade está em um estado de sitio como as pessoas da cidade de Oran, nelas, o mercado percebe uma oportunidade de ter bons negócios durante o período de pandemia, com o comércio ilegal e preços abusivo, conforme, pesquisa feita pelo Departamento Intersindical de Estística e Estudos Socioeconomicos (Dieese) no mês de maio de 2020, Pesquisa Nacional da Cesta Básica constatou que das 17 capitais pesquisadas a cesta basica teve um aumento em mais de 10, sendo os itens com maior aumento no preço; o arroz, feijão, e o leite, a pesquisa ainda revela que o trabalhador com remuneração com piso nacional, gastou 49,61\% do seu salário líquido com cesta básica, valores referente a uma pessoa adulta.

Do real para a literatura, em uma das falas do Sr. Cottard durante uma conversa com médico Rieux e Jean Tarrou, o Sr. Cottard diz: “... sinto-me bem na peste. Não vejo por que haveria de empenhar em fazê-la cessar” (CAMUS, p. 90). Com esta fala do personagem nos deparamos com o hoje e como a pandemia vem nos mostrando e reforçando as consequências de um sistema que, por décadas e séculos, vem sendo desenvolvido através de um meio de produção que divide a sociedade.

A atual crise distância ainda mais a classe dominante da classe dos despossuídos, esta que sempre sofreu com as condições precárias de vida, juntando se agora ao atraso tecnológico deixando claro o valor do trabalhador no sistema capitalista, este que não apenas explora a força de trabalho, como também induz nossas escolhas, ficando evidente o abuso na comercialização de produtos simples deixando claro o descaso 
com a vida, sem falar da difusão do medo na população, relacionado ao desabastecimento de alimentos no início da pandemia que foi outro motivo para inflar o preço dos alimentos básicos, afetando ainda mais as classes mais vulneráveis.

\section{Sr. Othon}

Através do personagem do Sr. Othon, um juiz com uma postura profissional, que teve seu filho vítima da doença, como forma de prevenção, as pessoas de sua família também foram separadas e isoladas como todos os cidadãos. "Para o juiz de instrução, porém, já não havia lugar senão no campo de isolamento que a prefeitura estava organizando, no estádio municipal, com o auxílio de barracas emprestadas pelo serviço de vigilância sanitária. Rieux pediu desculpas, mas o juiz disse que havia uma só regra para todos, e que era justo obedecer" (CAMUS, p. 118).

Em fevereiro de 2020, o novo coronavírus deixa de ser notícia da Europa e passa a ser realidade no Brasil, trazido pela classe mais alta que se deliciava no inverno europeu, não demorou muito para o vírus atingir os menos favorecidos.

Não deixando dúvidas que a história do Sr. Otton é bem diferente da realidade e que a frase clichê: "estamos todos no mesmo barco" não é verdade, pois mesmo o vírus não escolhendo quem contaminar, a classe social a que pertence o infectado, vai contar muito para sua cura.

De acordo com o texto de Mônica Martins (2020, n.p.), a pandemia expõe de forma escancarada a desigualdade social. Comparando o número de infectados e óbitos no início da pandemia na cidade de São Paulo, na região do "Morumbi, bairro nobre da burguesia foram registrados 297 casos positivos e 7 mortos, ao passo que em Brasilândia, bairro de operários e imigrantes os infectados somaram 89 e os mortos 54 pessoas", nos revelando que mesmo com o Sistema Único de Saúde (SUS),sendo o mais democrático do mundo, não consegue dar suporte a quem precisa, pois este vem sendo devastado ao longo de sua história com "políticas neoliberais". Em A pandemia de Covid-19 no Brasil: crônica de uma crise sanitária anunciada, Guilherme Loureiro Werneck e Marília Sá Carvalho (2020, p. 1) nos mostram que "num contexto de grande desigualdade social, com populações vivendo em condições precárias de habitação e saneamento, sem acesso sistemático à água e em situação de aglomeração", o poder devastador da pandemia produz números alarmantes de mortos.

Com a pandemia as desigualdades sociais tornam-se ainda mais nítidas, pois, ao contrário de uma porcentagem pequena da população, muitas pessoas vivem em aglomerados com famílias numerosas em comunidades e favelas trazendo ainda mais riscos para disseminação do vírus.

Ainda de acordo com Guilherme Loureiro Werneck e Marília Sá Carvalho (2020, p. 3) : “a epidemia de Covid-19 encontra a população brasileira em situação de extrema vulnerabilidade, com altas taxas de desemprego e cortes profundos nas políticas sociais", além dessas pessoas serem expostas com maior facilidade ao vírus para manterem seus trabalhos num país marcado pelo número de empregos informais, há também a instabilidade do trabalho que se constitui como problema tão sério quanto o precedente.

Conforme os dados da Pesquisa Nacional por Amostra de Domicílios Contínua (PNAD Continua), publicada pelo Instituto Brasileiro de Geografia e Estatística (IBGE), divulgada em fevereiro de 2020, "a taxa de informalidade - somada aos trabalhadores sem carteira, trabalhadores domésticos sem carteira, empregador sem CNPJ, conta própria sem CNPJ e trabalhador familiar auxiliar - atingiu seu maior nível desde 2016 no Brasil (41,1\%) em 20 Estados".

Essa situação escancara a desigualdade entre os brasileiros e em um confinamento forçado, o 
Governo Federal, depois de ser reivindicado pelos governadores, disponibiliza o auxílio emergencial baseado na Lei no 10835/2004, “a renda básica de cidadania”. Sendo o auxílio para trabalhadoras e trabalhadores que preenchem os requisitos do Decreto n 10316/2020, artigo 3º instituído pela Lei n ${ }^{\circ}$ 13982/2020 para assim receberem seiscentos reais durante três meses. $\mathrm{O}$ valor estabelecido assegura uma pequena parte da renda de muitas famílias, contudo está longe de diminuir qualquer desigualdade, principalmente em relação às medidas de proteção do distanciamento social, fazendo com que as classes sociais C, D e E não tenham a opção de se resguardarem dos riscos da contaminação.

Afinal, para proteger e ser protegido o mundo se rende ao afastamento social, porém fica a dúvida como fazê-lo num país tão desigual, em que a prioridade não parece ser a vida da população, mas o sacrifício social para a salvação do mercado.

\section{O isolamento}

Camus (p. 57) descreve a cidade de Oran: “....as pessoas tinham aceito estar isoladas do exterior como teriam aceito qualquer outro inconveniente temporário[...] Mas, subitamente [...] sentiam confusamente que essa reclusão lhes ameaçava toda a vida..." Essa descrição da cidade de Oran, qual uma verdadeira tomada de consciência que era preciso um exílio, modificou o cotidiano dos cidadãos da cidade e, da mesma forma, reconhecemos o período atual guiado pelas medidas e cuidados para combate do novo coronavírus.

Em primeiro lugar, esclarecemos a diferença entre quarentena, isolamento e distanciamento. A quarentena é quando a pessoa exposta a algum tipo de doença contagiosa, fica isolada por um período de tempo como medida de proteção. Em Pandemias muito além da Covid-19, Concilia Ortonano, através de uma curiosa análise etimológica, mostra a origem da palavra vinda do italiano quarantagiorni (40 dias), começou a ser usada no século XIV, a partir do momento em que autoridades portuárias italianas passaram a exigir que embarcações oriundas de países com surtos de Peste Negra (1346-1353) permanecem ancorados por 40 dias, até o desembarque". (ORTONANO, 2020, p. 16, 17).

Em segundo lugar, o isolamento acontece quando um indivíduo está doente e é colocado isolado para evitar contaminação. Em terceiro lugar, o distanciamento ou afastamento são medidas de proteção para dificultar a disseminação de doenças. No entanto, atualmente como forma de diminuir o avanço do novo coronavírus, a Organização Mundial da Saúde (OMS) viu no distanciamento social como seu maior aliado para conter o vírus, além da Portaria no 356/2020 que dispõe sobre o conjunto de medidas que foram adotadas para controlar o número de infectados pelo Covid-19 no país, juntamente com o período de quarentena de "14 dias" para as pessoas com investigação clínica e o afastamento social para diminuir o contágio pelo vírus por tempo indeterminado, para assim não sobrecarregar o sistema de saúde, mantendo apenas serviços essenciais: farmácia, supermercados, postos de combustíveis e hospitais abertos.

Decretos foram publicados por governadores e prefeitos fechando total ou parcialmente o comércio, como medidas de contenção do vírus ${ }^{2}$. Ação feita através de experiência trazida de outros países que sofreram primeiro com a mesma doença. Contudo, o assunto é motivo de muitas discussões entre especialistas em questões sociais, economistas, autoridades governamentais e profissionais da área de saúde.

20 que vimos desde o início da pandemia é uma situação precária do sistema de saúde em um país onde a maioria da população está em condição de pobreza. No entanto, o que se nota é uma briga de força entre governos e partidos políticos fazendo jogadas que beneficiem seus governos ou futuras candidaturas. Atinamos para medidas que estão sendo tomadas pelos governos federais, estaduais e municipais que muita das vezes negligenciam a curva epidêmica. Deixando claro o descanso com a vida. 
Um grupo defende o "isolamento vertical", onde as pessoas classificadas como grupo de risco, idosos e pessoas com doenças crônicas, ficariam isoladas. Todavia, em A pandemia de Covid-19 no Brasil: crônica de uma crise sanitária anunciada, Guilherme Loureiro Werneck e Marília Sá Carvalho nos apresenta a dificuldade de implementar o isolamento vertical (2020, p. 3):

... as condições para a execução de um "isolamento vertical" efetivo, na situação atual da epidemia no Brasil, são muito limitadas. Isso se dá, em parte, pela alta velocidade de expansão da infecção e as dificuldades para o monitoramento e vigilância estrita de casos e contatos, uma vez que a proporção de assintomáticos se aproxima de $80 \%$ dos infectados. [...] De fato, a experiência da China mostra que, no início da epidemia, cerca de $86 \%$ das infecções não foram detectadas, mas constituíram a fonte de infecção para cerca de 79\% dos casos. (CARVALHO, WERNECK, 2020)

Por outro lado, há os que acreditam que o “isolamento horizontal” é a melhor forma de amenizar a curva epidemiológica. Em A pandemia de Covid-19, o isolamento social, consequências na saúde mental e estratégias de enfrentamento: uma revisão integrativa pontua: "o isolamento social tem como principal objetivo restringir o contato entre as pessoas buscando reduzir as chances de contaminação do vírus e assim, a procura pelos serviços de saúde e o número de mortes" (ALQUINO et al.,2020 in PEREIRA et al., 2020).

O trecho nos esclarece o porquê do afastamento social em razão da alta transmissibilidade do vírus e nos faz lembrar de países como Itália, por exemplo, onde o afastamento foi adiado e viu milhares de pessoas morrerem com o vírus e seu sistema de saúde implodir, fazendo com que o país adotasse o distanciamento horizontal. Por sua vez, os professores Andrés Ferrari e André Moreira Cunha (2020, n.p), A pandemia de Covid-19 e o isolamento social: saúde versus economia dos professores mostram que o afastamento social é a medida que pode salvar o sistema de saúde: "se 50\% da população brasileira for infectada, teremos cerca de cinco milhões de pessoas que de mandarão atenção especial, um número que em muito excede a capacidade humana, material e de recursos hospitalares existentes no país".

Enfim, num país como o Brasil onde existem milhões de pessoas que vivem em situação vulnerável, conforme dados da Síntese de Indicadores Sociais (SIS) divulgado pelo Instituto Brasileiro de Geografia e Estatística (IBGE), no dia 06 de novembro de 2019, aponta que 13,5 milhões de pessoas vivem em extrema pobreza no país, com renda mensal per capita inferior a $\mathrm{R} \$ 145,00$, em uma realidade tão desigual a estatística mostra a importância do distanciamento social e como é preciso ser feito de forma consciente, fazendo pensar que em pleno século XXI para o bem comum é preciso um meio arcaico para nos salvarmos: o distanciamento, a volta para si e para dentro de casa.

\section{Considerações Finais}

Partimos da leitura d'A Peste que evidenciou sua grande importância como um momento de reflexão. Não deixamos de fazer comparações dos personagens da obra com a realidade que nos encontramos. Recordamos figuras fictícias e reais para pensarmos as condições do ambiente, a importância da pesquisa, dos profissionais que trabalham para combater o vírus e do cuidado de todas as pessoas. Com isso, reconhecemos novamente que nem o mercado nem o sistema privado de saúde complementar são capazes de preservar a vida da sociedade em tempos de pandemia.

Ademais, sem menosprezar a seriedade de algumas instituições privadas de ensino e pesquisa, a imensa maioria (quase que exclusivamente) que ainda investe em pesquisa para o bem social são as instituições públicas de ensino superior, enquanto tantas outras priorizam o lucro e a redução de gastos nesse 
momento, além de demitirem e reformularem seus quadros funcionais.

Portanto, a nossa realidade mostra a importância de pesquisas feitas pelas Universidades tão depreciadas neste momento pelo atual Governo Federal e todo o seu gabinete do ódio presente no MEC, o que confirmamos junto à pesquisa desenvolvida pela Ranking Universitário Folha (RUF2019) observando que dentre de 1 a 20 das melhores universidades brasileiras 18 são públicas.

Camus, lido à luz das demandas sociais, nos faz observar a importância do Sistema Único de Saúde (SUS) e a grandiosidade do país, em que a concentração de riqueza em certas regiões do país, aguçam a desigualdade social. Conforme o Conselho Federal de Medicina (CFM) destacou em 2018: "menos de 10\% dos municípios brasileiros possuem leito de UTI”. Sabendo que estes são imprescindíveis para o tratamento de parte das pessoas que são acometidas pelo Covid-19, além do fato de "os leitos de Unidade de Terapia Intensiva em estabelecimentos públicos, conveniados ao Sistema Único de Saúde ou particulares estarem disponíveis em somente 532 dos 5570 municípios brasileiros"”, com concentração maior das UTI's na região sudeste, além das instalações provisórias em hospitais de campanha em todo o país, mas que ainda é insuficiente caso haja um aumento no número de infectados. Mesmo o SUS sendo o sistema de saúde mais democrático que existe, ele não suportaria um aumento desordenado por demanda de leitos.

Assim, repete-se uma triste realidade: o capital se mostra muito mais importante que as vidas, de forma ilusória, nos faz acreditar que a riqueza é distribuída de acordo com o mérito de cada indivíduo, no processo de produção. Todavia, no texto de Reinaldo A. Carcanholo, Sobre a ilusória origem da mais-valia (p. 57) aponta que “...a teoria marxista do valor tem como consequência necessária a conclusão de que o excedente econômico capitalista e, em particular, o lucro, é fruto da exploração do trabalho não pago..." claramente observamos como o sistema capitalista é uma violência contra o trabalhador e sempre beneficiará com privilégios à classe dominante.

A desigualdade social impossibilita o acesso de pessoas aos suprimentos básicos como água, sabão e alimentos. Infelizmente impedindo a quarentena ou o isolamento adequado, intensificando a contaminação pelo vírus.

Notavelmente, o livro mostra a realidade, o desespero e a incerteza das pessoas. Com o afastamento social muitos de nós teremos como compreensão do mundo que com uma rotina agitada seria dificilmente notada. Expõe as mais intensas faces das desigualdades sociais. Revelando a verdadeira face de cada um e a instrumentalização do Estado a serviço da manutenção do mercado.

\section{Referências}

AGENCIA IBGE. Carmen Nery. Extrema pobreza atinge 13.5 milhões de pessoas e chega ao maior nível em 7 anos. publicado 06/11/2019 última atualização 07/11/2019. Disponível: <https:// agenciadenoticias.ibge.gov.br/agencia-noticias/2012-agencia-de-noticias/noticias/25882-extrem a-pobreza-atinge-13-5-milhoes-de-pessoas-e-chega-ao-maior-nivel-em-7-anos> Acesso em: 08/10 12020

AUTRES BRÉSILS. ABJD- Associação Brasileira de Juristas pela democracia. Bolsonaro commet un crime contre l'humanité: la plainte est déposée devant la Cour pénale Internationale. 8 de abril de 2020. Disponível em <https://www.autresbresils.net/Bolsonaro-commet-un-crime-contre-l-humanite-la-plainte-est-deposee-devant-la> Acesso em 22/07/2020.

DIEESE. Departamento Intersindical de Estatística e Estudos Socioeconômicos. Tomada especial de preços de maio de 2020. Disponivel em:< https://www.dieese.org.br/> Acesso em 08/10/2020 
BRASIL. Decreto 10316 de 2 de Abril de 2020.Regulamenta a Lei nº 13.982, de 2 de abril de 2020. Publicado no Diário Oficial da União. Brasília/DF. Disponível em <https://modeloinicial.com.br/ lei/DEC-10316-2020/decreto-10316/art-3> Acesso em 06/06/20.

BRASIL. Decreto-Lei n 399. 30 de Abril de 1938. Publicado no Diário Oficial da União. Brasília/DF 07/05/38. Disponivel em: <https://www2.camara.leg.br/legin/fed/declei/1930-1939/decretolei-399-30-abril-1938-348733-publicacaooriginal-1-pe.html> Acesso em 06/06/20.

BRASIL. Lei n 10835 de 8 de Janeiro 2004. Institui a renda básica de cidadania e dá outras providências. Brasília/DF. Disponível em <http://www.planalto.gov.br/ccivil_03/_ato2004-2006/20 04/lei/l10.835.htm> Acesso em 06/06/20.

BRASIL. Portaria n 188. 3 de Fevereiro 2020. Diário Oficial da União. Publicado em: 04/02/2020. Brasília/DF. Disponível em <http://www.in.gov.br/en/web/dou/-/portaria-n-188-de-3-de-fevereirode-2020-241408388> Acesso em 24/05/2020.

BRASIL. Portaria n 356, 11 de Março de 2020. Diário Oficial da União. Publicado 12/03/20. Brasília/DF. Disponível em <http://www.in.gov.br/en/web/dou/-/portaria-n-356-de-11-de-marco-de2020-247538346> Acesso em 06/06/20.

BRASIL. Presidência da República. Pronunciamento do Senhor Presidente da República, Jair Bolsonaro, em cadeia de rádio e televisão, 24 mar. 2020. Disponível em <https://www.gov.br/planalto/pt-br/acompanhe-o-planalto/pronunciamentos/pronunciamentos-do-presidente-da-republi $\mathrm{ca} /$ pronunciamento-em-cadeia-de-radio-e-televisao-do-senhor-presidente-da-republica-jair-bolsonaro>. Acesso em 27/05/20.

CAMUS, A. A Peste. Disponivel em <http://lelivros.love/book/download-a-peste-albert-camus-eme-pub-mobi-e-pdf/> Acesso em: 24/05/20.

CARCANHOLO, R. A. Sobre a ilusória origem de mais valia. Publicado no VI Encontro Nacional de Economia Política do SEP. São Paulo. Junho 2001. Disponível em <https://www.ifch.unicamp.br/criticamarxista/arquivos_biblioteca/artigo9676_merged.pdf> Acesso em 24/05/2020.

CARVALHO, M. S. \& WERNECK, G. L. A pandemia de Covid-19 no Brasil: crônica de uma crise sanitária anunciada. Cadernos de Saúde Pública. 36 n 5 . Rio de Janeiro. Maio 2020. Disponível em <https://www.scielosp.org/article/csp/2020.v36n5/e00068820/pt/> Acesso em:08/06/20.

DE SOUSA JÚNIOR, João Henriques et al. Da Desinformação ao Caos: uma análise das Fake News frente à pandemia do Coronavírus (COVID-19) no Brasil. Cadernos de Prospecção, v. 13, n. 2 COVID19, p. 331, 2020.

DE TROI, M. e QUINTILIO, W. Coronavírus: lições anti-negacionistas e o futuro do planeta [online]. SciELO em Perspectiva, 2020. Disponível em <https://blog.scielo.org/blog/2020/03/31/coronavirus-licoes-anti-negacionistas-e-o-futuro-do-planeta/>. Acesso em: 08/06/20.

DOWBOR, L. 0 que é capital? Editora Brasiliense. São Paulo, 10 edicao. Revista e ampliada em 2004. Disponivel em: <https://dowbor.org/2003/09/ladislau-dowbor-o-que-e-capital-2003.html />. Acesso em: 10/10/2020

FERRARI, A. e CUNHA, A. M. A pandemia do Covid-19 e o isolamento social: saúde versus economia. Faculdade de Ciências Econômicas (UFRGS), 26 de março de 2020. Disponível em <https://www. ufrgs.br/fce/a-pandemia-do-covid-19-e-o-isolamento-social-saude-versus-economia/>. Acesso em 04/06/ 2020.

IBGE. BRASIL. Pesquisa Nacional por Amostra de Domicílios Continua, fevereiro 2020. Publicado 31/03/20, última atualização 31/03/20. Disponível em <https://agenciadenoticias.ibge.gov.br/ 
agencia-sala-de-imprensa/2013-agencia-de-noticias/releases/27259-pnad-continua-taxa-de-desocupacao-e-de-11-6-e-taxa-de-subutilizacao-e-23-5-no-trimestre-encerrado-em-fevereiro-de-202 0> Acesso em: 06/06/20.

MARTINES, C. M. Evolução nos tempos do coronavírus, Ser Médico, São Paulo, n 90, Jan/Fev/Mar 2020, v 14,15. Disponível em <https://www.cremesp.org.br/library/modulos/flipbook/revista/ 90/14-15/index.html\#zoom=z>. Acesso em 25/05/2020.

MARTINS, M. D. A pandemia expõe de forma escancarada a desigualdade social. Secretaria de Ciência, Tecnologia e Educação Superior. Publicado em 25 de Abril 2020. Disponível em <https:// www.sct.ce.gov.br/2020/04/25/a-pandemia-expoe-de-forma-escancarada-a-desigualdade-social/>. Acesso em 02/06/20.

MINISTÉRIO DA SAÚDE. BRASIL. Painel Coronavírus. Disponivel em <https://covid.saude.gov.br/> Acesso em 25/05/2020.

MINOWA, E.et al. Coronavirus: A falência do sistema capitalista e a defesa radical do SUS. Revista Movimento. Publicado 16 de Março. São Paulo. Disponível em <https://movimentorevista.com. br/2020/03/coronavirus-falencia-sistema-capitalista-defesa-radical-sus/> Acesso em 25/05/202 0 .

MOUTINHO, L. et al. ScientificProduction in Times of Coronavirus. Revista de Antropologia, v. 63, $n^{\circ}$ 1, p. 7-11, 2020.

OPAS BRASIL. Organização Pan Americana da Saúde. OMS afirma que Covid-19 é agora caracterizada como pandemia. Puplicado: 11 de março de 2020. Disponível em <https://www.paho.org/ bra/index.php?option=com_content\&view=article\&id=6120:oms-afirma-que-covid-19-e-agora-caracterizada-como-pandemia\&Itemid=812> Acesso em 25/05/2020.

ORTANANO, C. Pandemias muito além da Covid-19. Ser Médico, São Paulo, n 90, Jan/Fev/Mar 2020, v. 14,15. Disponível em <https://www.cremesp.org.br/library/modulos/flipbook/revista/ 90/14-15/index.html\#zoom=z>. Acesso em 25/05/2020.

PEREIRA, M. D. et al. A pandemia de Covid-19, o isolamento social, consequências na saúde mental e estratégias de enfrentamento: uma revisão integrativa. UNIT - Universidade Tiradentes. Publicado em: 21/05/20. Disponível em <https://portal.unit.br/blog/noticias/a-pandemia-da-covid-19o-isolamento-social-consequencias-na-saude-mental-e-estrategias-de-enfrentamento-uma-revisaointegrativa/> Acesso em 01/06/20.

RUF2019. Ranking Universitário Folha. Disponível em: https://ruf.folha.uol.com.br/2019/rankingde-universidades/principal/ Acesso em: 10/10/2020

SOUSA JR., J. H. et al. Da Desinformação ao Caos: uma análise das Fake News frente à pandemia do Coronavírus (COVID-19) no Brasil. Cadernos de Prospecção, v. 13, n. 2 COVID-19, p. 331, 2020.

TOSTES, A. e MELO FILHO, H. Pandemia e nova Ordem Social, Quarentena: Reflexões sobre a Pandemia e Depois. Projeto Editorial Praxis. 1ed. Bauru: Canal 6 Brasil, 2020.

Artigo recebido em: 17 de agosto de 2020

Artigo aceito em: 15 de outubro de 2020 